\title{
Displaying Health Status Based IoT
}

\author{
Muhammad Arief Azizi ${ }^{1}$, Asnazulfadhli Zariman ${ }^{1}$, Ismail Yusuf Panessai ${ }^{1}$, Achmad Yani ${ }^{2}$ \\ ${ }^{1}$ Department of Computing, Faculty of Arts, Computing and Creative Industry, \\ Universiti Pendidikan Sultan Idris, Malaysia. \\ ${ }^{2}$ Fakultas Teknik, Universitas Hasanuddin. Indonesia.
}

Article history

Received:

02.01 .2020

Revised:

11.02.2020

Accepted:

16.03 .2020

*Corresponding Author: Muhammad Arief Azizi, Email:

arief3010@gmail.com

This is an open access article, licensed under: $\mathrm{CC}-\mathrm{BY}-\mathrm{SA}$
Abstract: Students have many activity in their daily life. There are many things to do like going to class, meeting for group assignment, shopping for food and so on. If the student is unwell then need to go to the clinic for treatment and leaving letter. So in order to reduce the risk of receiving illness, researchers propose Displaying Health Status Based on the Internet of Things Concept. This tool will help students by knowing the pulse rates is normal or not. Displaying Health Status Based on the Internet of Things is designed to facilitate students to see their pulse rate. This tool will also help students to develop their potential and facilitate the health of students themselves by knowing their pulse rate at the proper level. Students will always keep their health healthy for everyday life. Additionally, this tool can alert students that health is essential for life. The results of this research show that this tool can be used when exercising to determine the pulse rate is normal or not.

Keyword: Health Status, Internet of Things, Pulse Rate. 


\section{Introduction}

Displaying Health Status Based on the Internet of Things Concept is designed to facilitate students to see their pulse rate. This tool will also help students to develop their potential. This tool can facilitate the health of students themselves by knowing their pulse rates at the proper level. For example, students will always keep their health healthy for everyday life. This is because as a student, there are many things to do like going to class, meeting for group assignment, shopping for food and so on. If the student is unwell then need to go to the clinic for treatment and leaving letter. Besides that, students with poor health have higher probability of school failure, grade retention, and dropout [1].

Displaying Health Status Based on the Internet of Things Concept can help students to know their pulse rates at normal levels by using pulse and hand held sensors as a display. Users of this tool can see their pulse rate just put a pulse sensor on the wrist and need to open pulse detector apps. This tool is expected to be able to go further and be able to use it as best as possible and help students better health themselves. Additionally, this tool can alert students that health is essential for life. Students can use this tool at all times and plan their health. With this tool, students are able to plan their daily life to ensure that they stay healthy.

The scope of this tool has been recommended to everyone to use it. This tool is intended to ensure that the individual's health is primarily a student. This is because health is very important today. If not taking care of health, it will lead to a variety of diseases such as fever and high blood pressure. Displaying Health Status Based on the Internet of Things Concept is designed and developed in the hope that it will meet the needs of students who want to know the health of themselves as well as to develop the potential of students.

\section{Methodology}

For this first stage, information gathering has been carried out by surfing various websites to find out the necessary items as well as the selection and purchase of goods to complete the research. Purchase of goods is divided into two categories. The first category is a wholesale purchase. This is because there are items needed for wholesale prices and some items are the same. This way can save time and get a good price. The second category is another item from the first category. In order to avoid wastage, these items are sought after to complete the research.

\subsection{Requirement Analysis and Specification The Way Specifications Helped}

Specification of Displaying Health Status Based on the Internet of Things Concept has been generated through the identified problem statement. The problem statement that has been identified here is the time constraints and time of the students because they are busy with their work and students rarely care about their health. Students who want to know their health need to spend some time even temporarily to check their heart rate. It will make the students forget about their health and this will risk them in dangerous diseases. In addition, students will go to a nearby clinic to see treatment rather than knowing their health first, though there are many facilities to take care of their health.

With the existence of the Displaying Health Status System Based on the Internet of Things Concept, it can help to solve problems faced by students. It is because the tool can help students to know their heart rate and prevent them from going to clinic. Additionally, this tool can also help reduce money to buy medicines in the event of a disease.

The idea of making this tool is derived from existing pulse-measuring devices in the market. This tool is made on a small scale so users can buy it. An expensive pulse-measurement tool for students to buy because they are not harmful. So, for solving this problem, this tool is made to ease the students so as not to spend large amounts of money to buy existing pulse tools.

\section{Communication with Consumer}

Communication with students is that the observation conducted on the sample are mostly students of Universiti Pendidikan Sultan Idris (UPSI). In addition, communication with lecturers is also conducted through a weekly meeting in the lecturer's room. Through their joint communication, it is found that the Displaying Health Status Based on the Internet of Things Concept is appropriate and consistent with the objectives, functions, problem statements, scopes and modules that have been stated. Most of them think that Displaying Health Status Based on the Internet of Things Concept has the potential to go further and explore more deeply. 


\section{Constraint}

Among the constraints that arise before the implementation of Displaying Health Status Based on the Internet of Things Concept is the time constraints and times due to their busy work resulting in insufficient time. Therefore, Displaying Health Status Based on the Internet of Things Concept is created to display and record their heart rate by using a more systematic mobile phone.

In addition, the constraints arising during the implementation of the tool is when the purchased item does not arrive at the time set. In addition, the purchased item is damaged or does not work properly. Furthermore, constraints arising after the implementation of Displaying Health Status Based on the Internet of Things Concept is the occurrence of damage to the tool. This tool does not display their pulse rate on the mobile phone and this makes it forced to buy new items to continue the research.

\section{Rational}

Rationale for Displaying Health Status Based on the Internet of Things Concept is hoped that this tool in the future can be improved, especially in terms of adding tools for more features that can be used and can be adopted by students or parties concerned. It is also expected that the implementation of this tool can be completed and repaired in the future.

Implementation of Displaying Health Status Based on the Internet of Things Concept is to facilitate the students to maintain their health so that they can always have a healthy body to live the daily life of this globalization era.

\section{Specification of Details}

Displaying Health Status Based on the Internet of Things Concept is based Heart Beat Detector gives Beats per Minute (BPM) of a person using a Pulse Sensor. The Pulse Sensor will measure the change in volume of blood, which occurs when every time heart pumps blood in the body. This change in volume of blood causes a change in the light intensity through that organ. The Arduino will then convert this change into the heart beat per minute (BPM) [2]. It can be periodically used by heart patients and health conscious persons. This BPM data is transferred into ThingSpeak online server via ESP8266 Wi-Fi module. This data can be seen by the person by just signing into ThingSpeak account. Thingspeak is a web based open API IoT source information platform that comprehensive in storing the sensor data of varied 'IoT applications' and conspire the sensed data output in graphical form at the web level [3]. The previous data is also stored in the server. So, the people can periodically monitor their heart rate.

\section{Design}

The second stage is the design process. For this stage, several diagrams have been designed and prepared to develop the tool. Among the diagrams researchers have designed is the schematic diagram. The figure was designed to facilitate and illustrate the idea and travel of the tool in the development and implementation of Displaying Health Status Based on the Internet of Things Concept.

Displaying Health Status Based on the Internet of Things Concept is designed through the implementation process. The coding of this functional tool has been built using $\mathrm{C}++$ coding. This code has been built using Arduino IDE and Notepad ++ software. The Arduino IDE is written in the Java language and is based on the language named Processing or Wiring [4]. Through user-friendly processes, several UPSI students are testing the Displaying Health Status Based on the Internet of Things Concept and get results of the study on this tool. Then, the process is development. Through this process, Displaying Health Status Based on the Internet of Things Concept can be repaired after the results of the research were conducted several times and samples were obtained.

Arduino is the basic platform this research works on. ESP8266 Wi-Fi module takes analog values from the Pulse Sensor and upload the data into ThingSpeak server over Internet with a small battery connected to it as a power source. The Pulse Sensor detects the Beats per Minute (BPM) of a person. The circuit is wired up with a $10 \mathrm{~K}$ Ohm Resistor and a 10 Microfarad Capacitor. Resistors are used for voltage regulations and capacitor is used to reduce the voltage buffer, so that noise from Pulse Sensor can be reduced when ESP8266 collects the analog data. 
Muhammad Arief Azizi, Asnazulfadhli Zariman, Ismail Yusuf Panessai, Achmad Yani.

\subsection{Schematic Diagram}

This is schematic diagram for this research is shown in Figure 1.

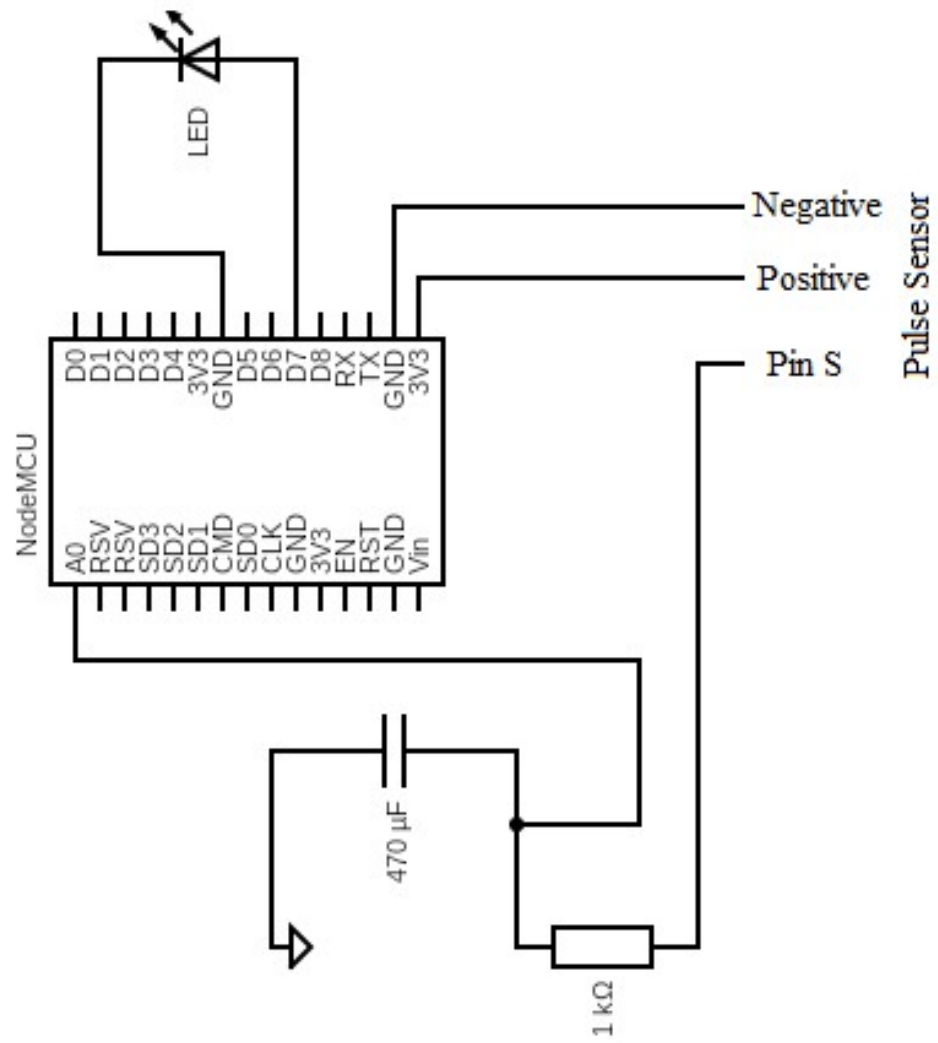

Figure 1. Schematic Diagram

\subsection{Component}

Components that been use in this research are:

\section{Pulse Sensor}

Pulse Sensor is straight forward, but positioning it in the right way matters. The flat side of the Sensor should be placed on top of the vein and a slight presser should be applied on top of it, normally clips or Velcro tapes are used to attain this pressure. Pulse Sensor is shown in Figure 2.

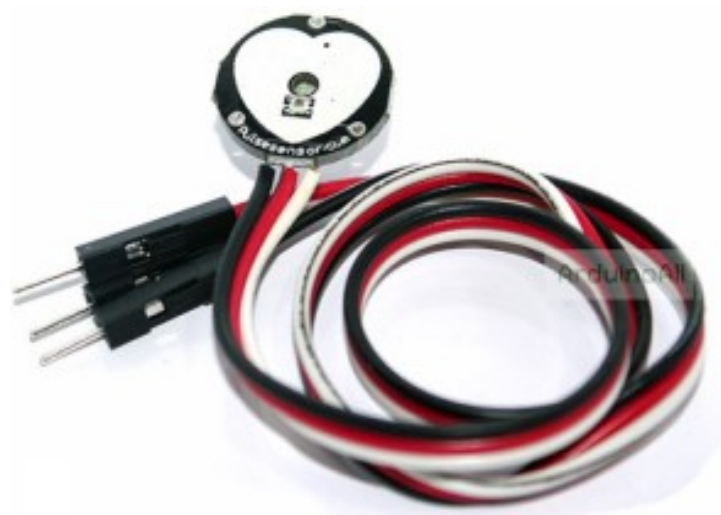

ESP8266 Node MCU

Figure 2. Pulse Sensor

ESP8266 Node MCU is an open source Internet of Things (IoT) platform for helping human communicates both human and the devices electronically with respect to control module [5]. It 
includes firmware which runs on the ESP8266 Wi-Fi SoC from Espressif Systems and hardware which is based on the ESP-12 module. It can be concluded that the ESP8266 Node MCU function is to connect to personal Wi-Fi just like Broadband. When connect to Wi-Fi, then data can be sent. ESP8266 Node MCU is shown in Figure 3.

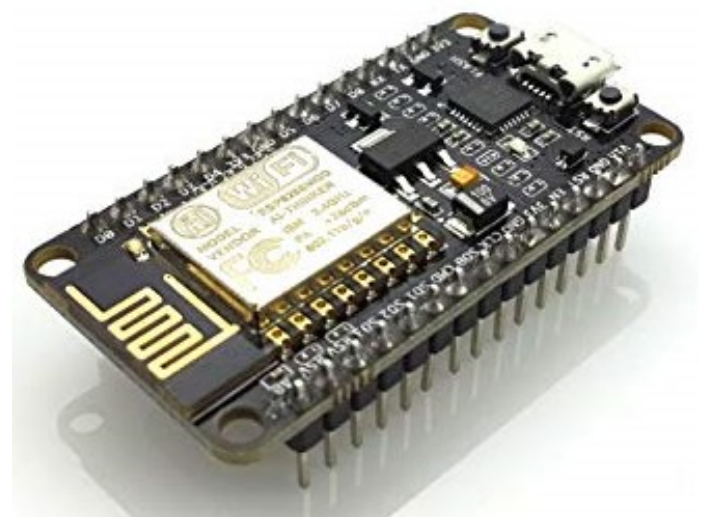

Figure 3. ESP8266 Node MCU

\section{Microfarad Capacitor}

The Farad is the SI derived unit of electrical capacitance, the ability of a body to store an electrical charge. Capacitors have two main applications, one of which is a function to charge or discharge electricity [6]. Microfarad Capacitor is shown in Figure 4.

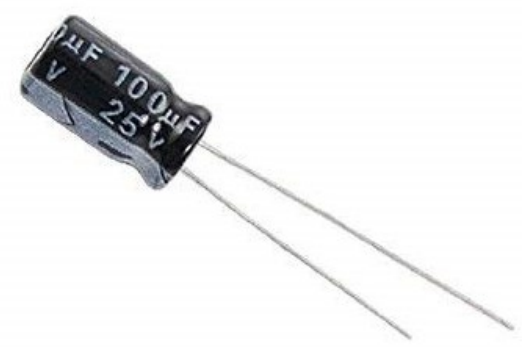

Figure 4. Microfarad Capacitor

\section{$L E D$}

LED is a small light. It stands for light emitting diode that works with relatively little power. The first known report on a light-emitting solid-state diode was made in 1907 by the British researcher H. J. Round [7]. The LED is shown in Figure 5.

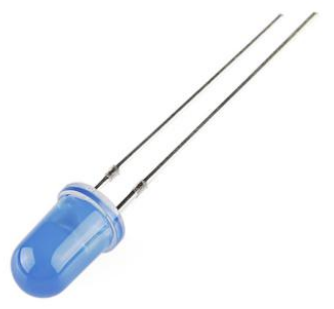

Figure 5. LED 


\section{$1 k$ Resistor}

Resistor is used to reduce current flow, adjust signal levels, to divide voltages, bias active elements, and terminate transmission lines among other uses. A series resistor is used to limit the amount of forward current [8]. 1k Resistor is shown in Figure 6.

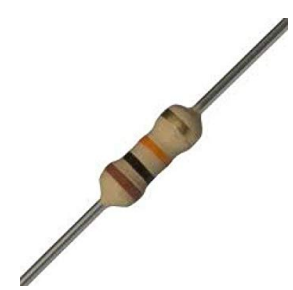

Figure 6. 1k Resistor

\section{Breadboard}

Breadboard is used to place all component and acting as circuit. A Breadboard is used to make up temporary circuits for testing or to try out an idea. No soldering is required so it is easy to change connections and replace components $[9,10]$. The Breadboard is shown in Figure 7.

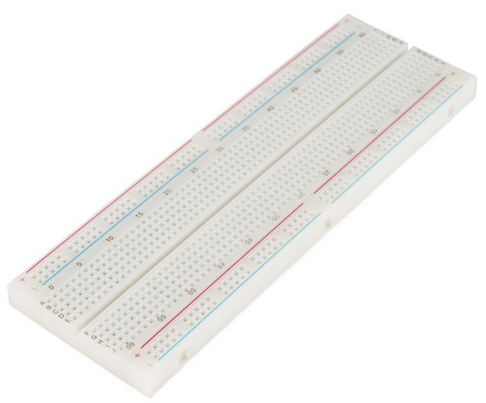

Figure 7. Breadboard

\subsection{Design of Tools}

The display of the tool from frontal view is shown in Figure 8.

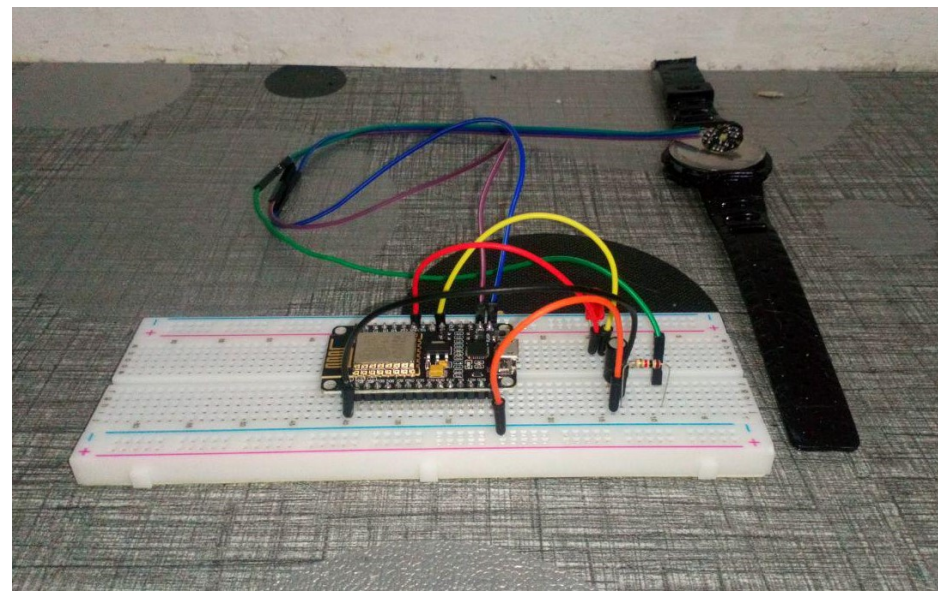

Figure 8. Frontal View 
Muhammad Arief Azizi, Asnazulfadhli Zariman, Ismail Yusuf Panessai, Achmad Yani.

The display of the tool from the top view is shown in Figure 9.

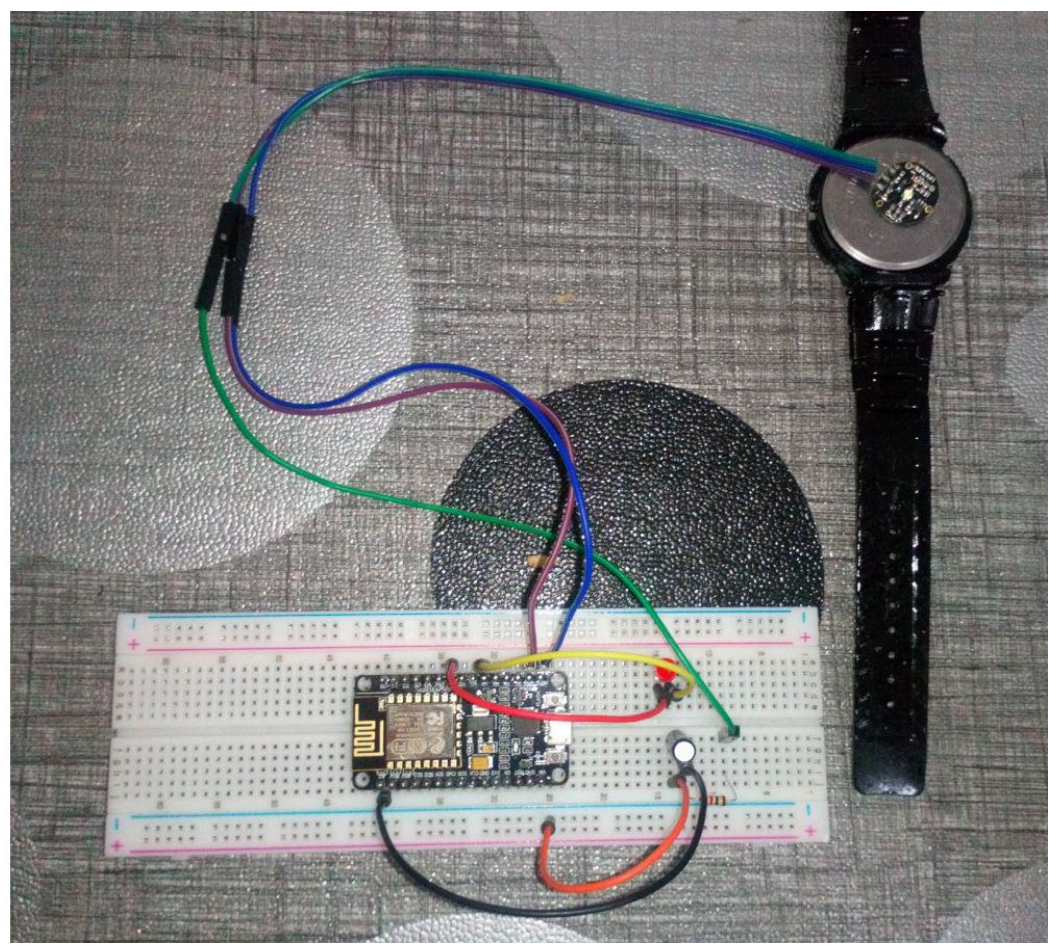

Figure 9. Top View

\subsection{Setup ThingSpeak Server}

Step to create a channel using ThingSpeak is shown in Figure 10.

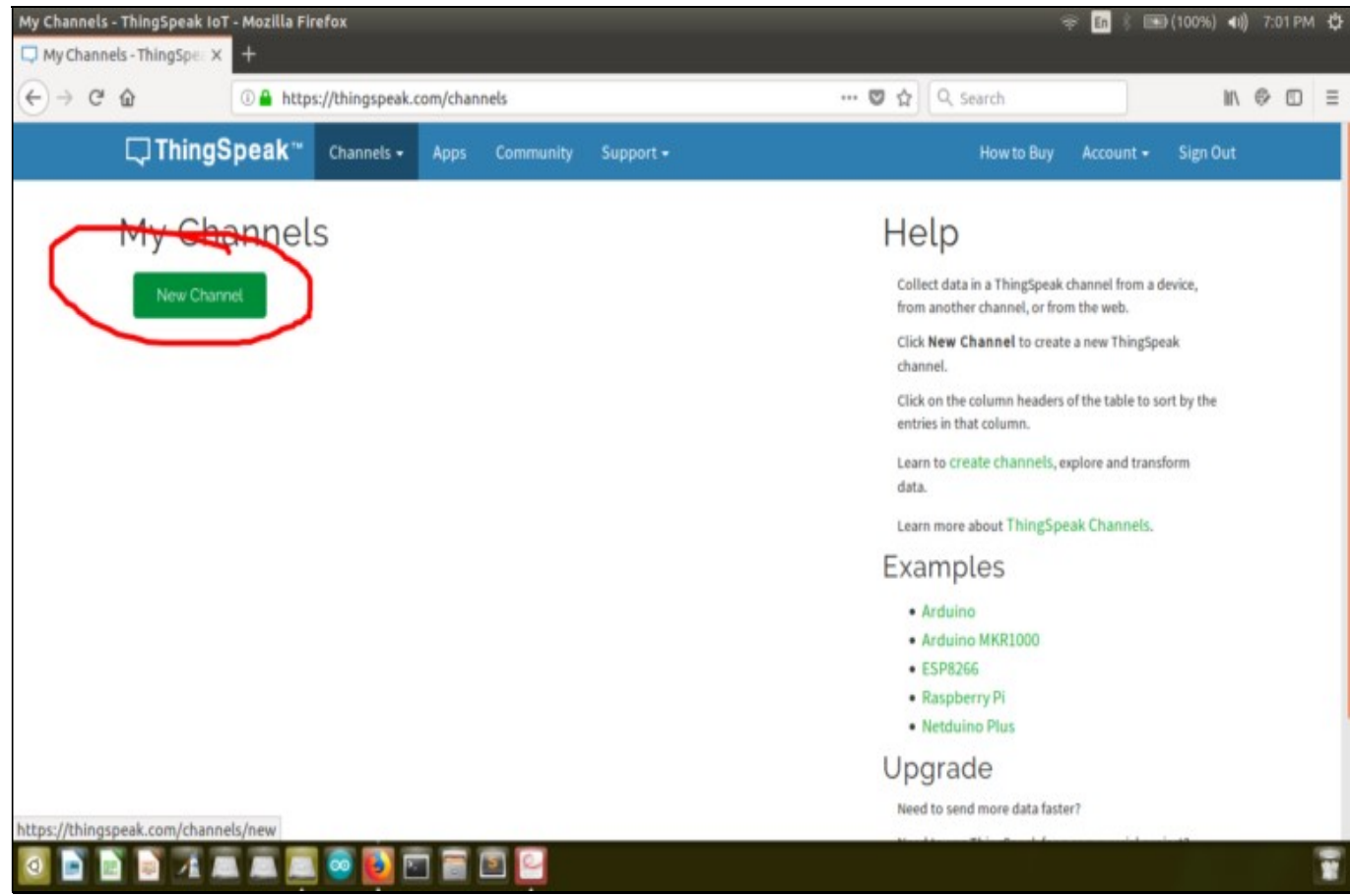

Figure 10. ThingSpeak Create Channel 
Muhammad Arief Azizi, Asnazulfadhli Zariman, Ismail Yusuf Panessai, Achmad Yani.

Step to create new channel heart rate field is shown in Figure 11.

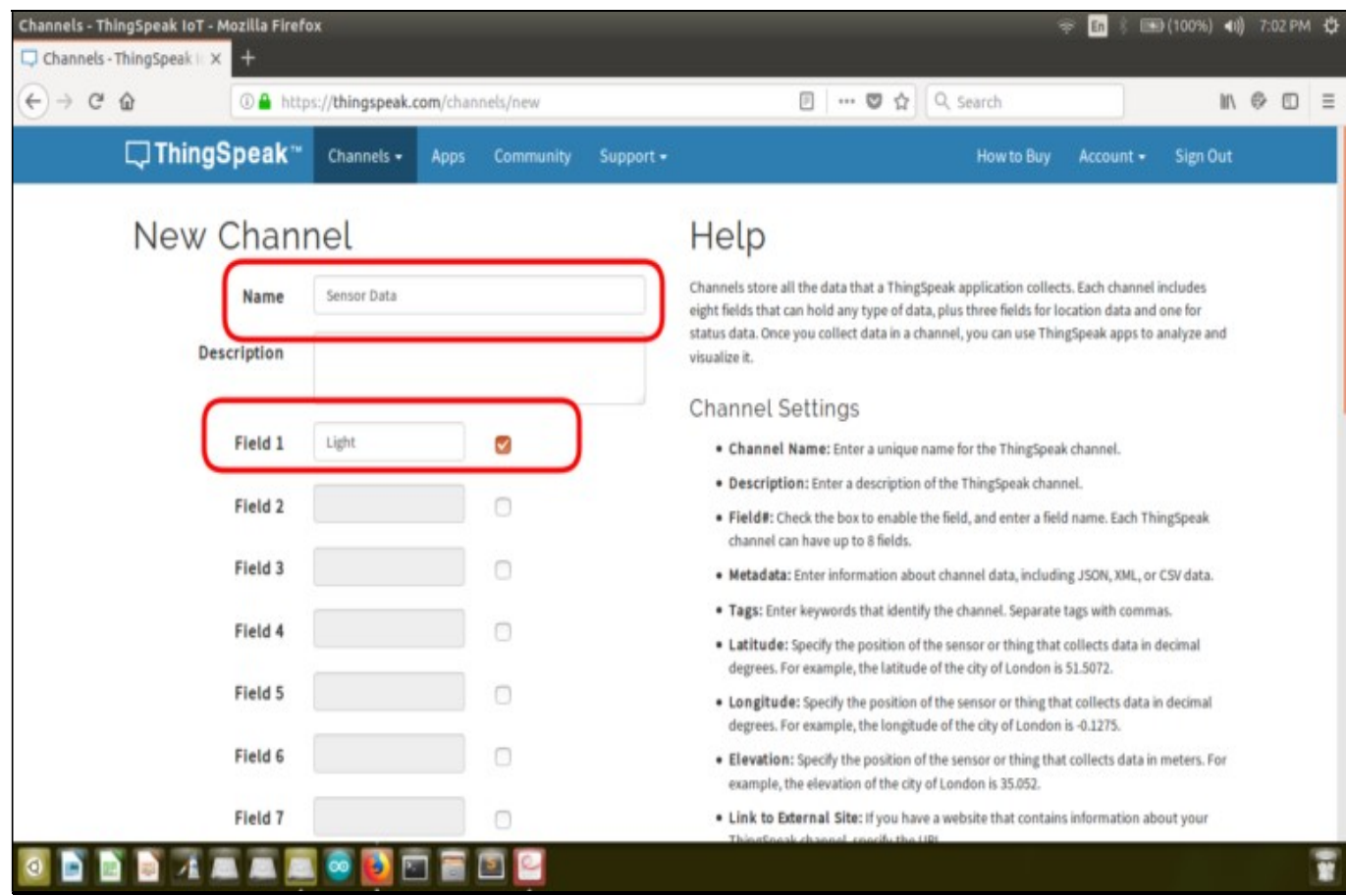

Figure 11. Creating New Channel Heart Rate Field

Step to Save channel is shown in Figure 12.

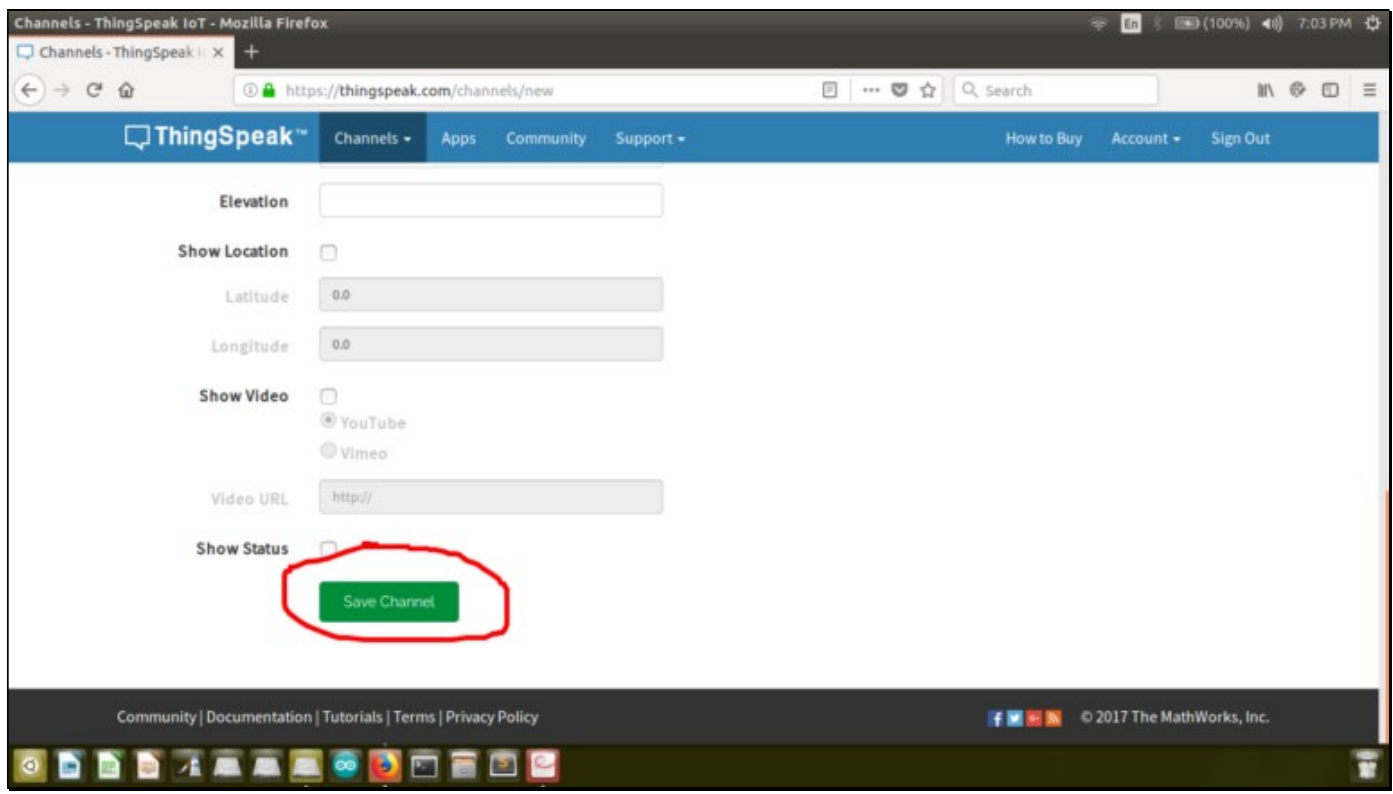

Figure 12. Save Channel 
Muhammad Arief Azizi, Asnazulfadhli Zariman, Ismail Yusuf Panessai, Achmad Yani.

Step of copy API key channel and paste on coding is shown in Figure 13.

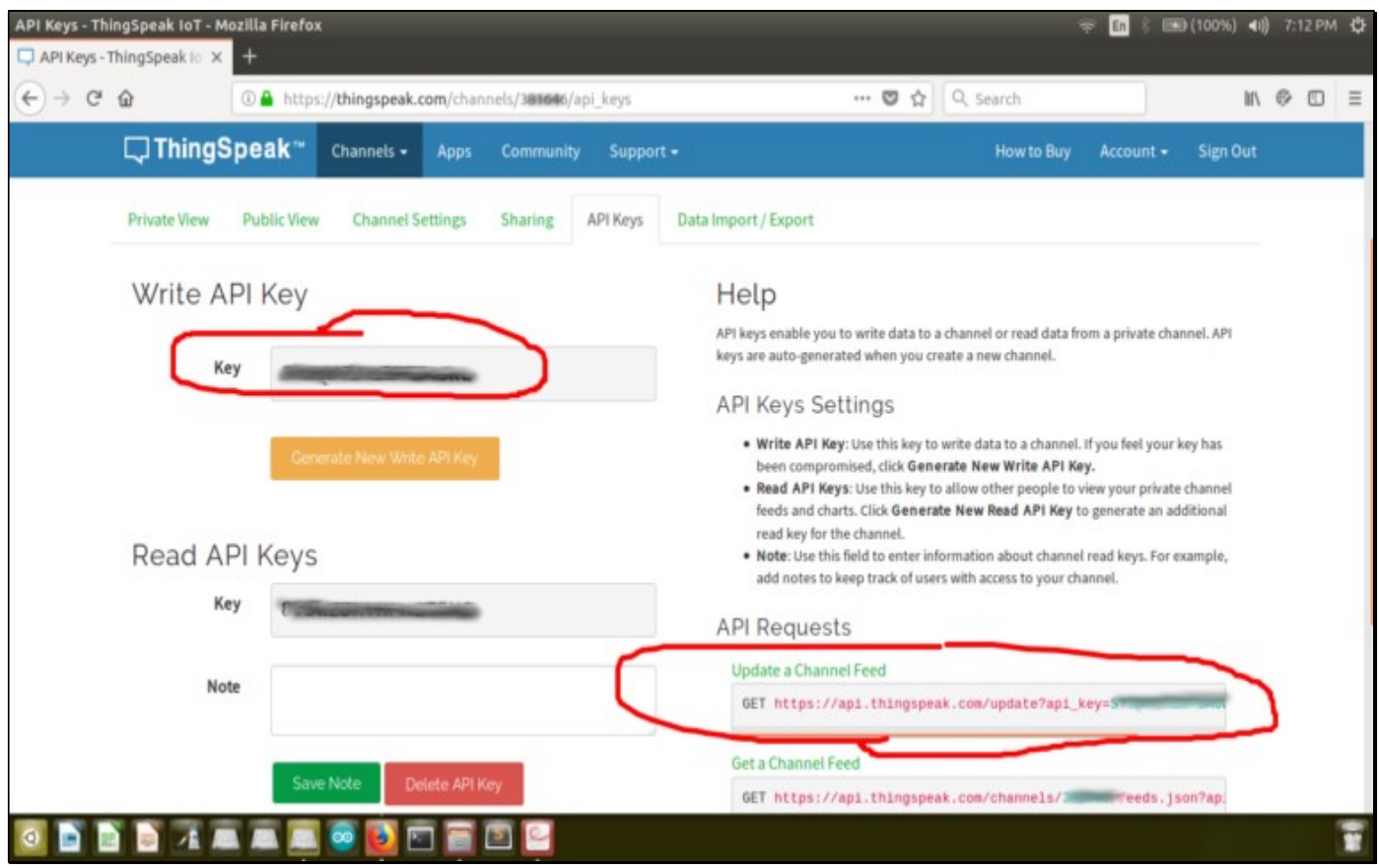

Figure 13. Copy API Key Channel and Paste on Coding

\subsection{Implementation}

For the third stage, the development and implementation of Displaying Health Status Based on the Internet of Things Concept was built using $\mathrm{C}++$ coding. This code was built using software like Arduino IDE and Notepad ++.

\subsection{Testing}

At this stage, information gathering has been implemented by participating in certain forums to solve problems. Displaying Health Status Based on the Internet of Things Concept has been tested several times to find out the problem. In addition, information gathering is also done by interacting with senior UPSI or contact with students from other institutions who have done the same research.

\subsection{Renewal}

At this stage, Displaying Health Status Based on the Internet of Things Concept has been restored based on observations and experiments that have been done several times to improve this research.

\section{Result}

Displaying Health Status Based on the Internet of Things Concept has managed to achieve the objectives of the research. This can be used by heart patients and people who are health conscious to monitor their heart rate regularly. Students can see their pulse rates on mobile phones. The test uses Wi-Fi connection to send pulse rate to mobile phone. It is because the component ESP8266 Node $\mathrm{MCU}$ is a tool for connecting personal Wi-Fi or Wi-Fi surrounds.

This test is done several times in order to connect with Wi-Fi. In addition, Pulse Sensors also performed several tests to identify the component with proper pulse readings. The tests performed were Pulse Sensors tested on some compact circuits. The result are shown in graph that have build whenever the data been send to the server. The display of heart rate is shown in Figure 14. 


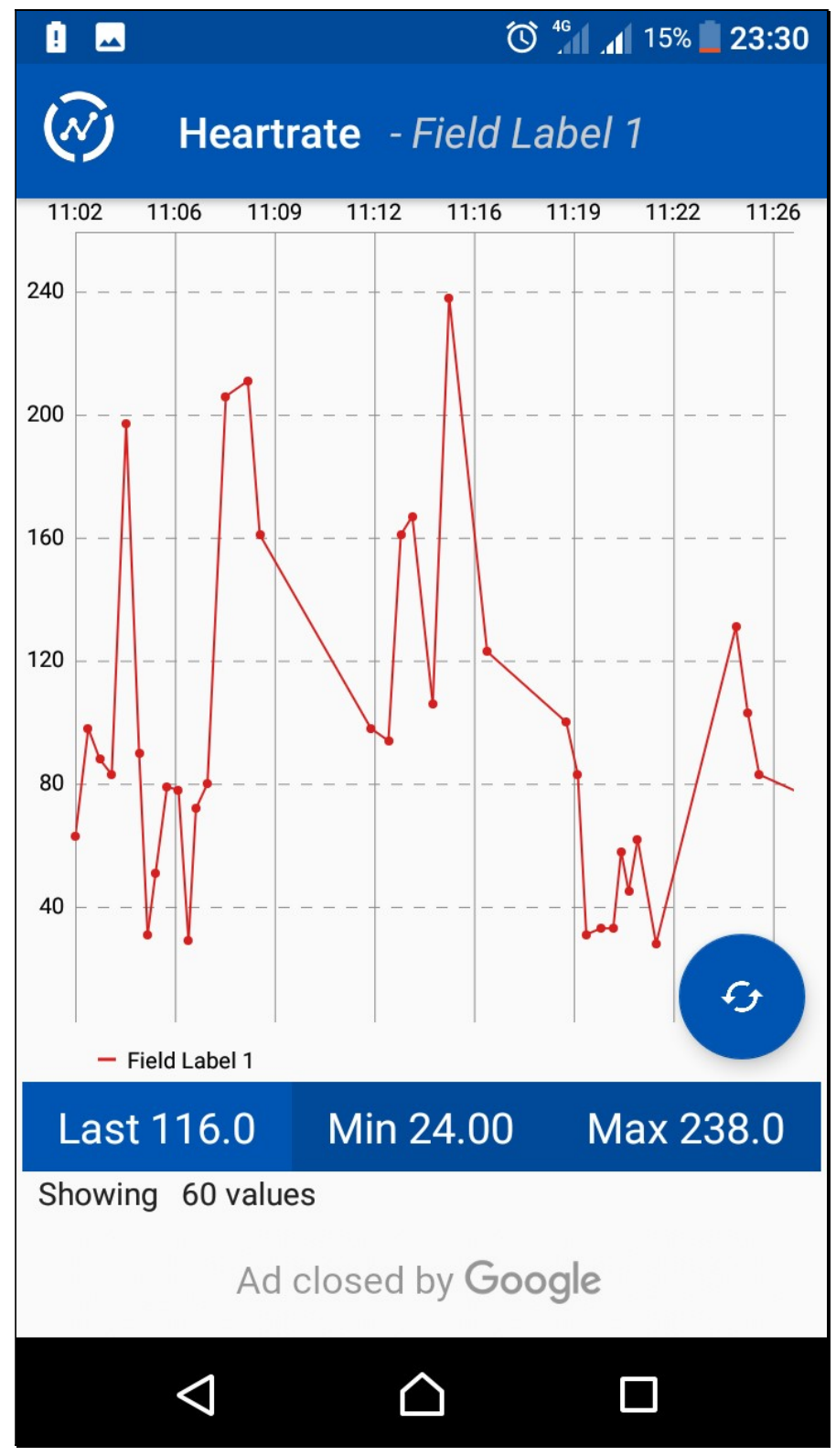

Figure 14. Display Heart Rate with Graph

Displaying Health Status Based on the Internet of Things Concept aims to make easier for students to check their pulse rate without buying existing pulse-measuring devices in the market. Furthermore, in this era of globalization, mobile phones are essential in everyday life as well as facilitating students to see their pulse rate. Using Internet, data can be made available for remote use and only authorized user like remote specialist doctor for special advice as well.

Displaying Health Status Based on the Internet of Things Concept allows students to check their pulse rate and look at the mobile phone. This tool is also a portable device because it can be placed on hand. This tool can make it easier for students to manage their health to follow their self-reading.

This tool can be used when exercising to determine the pulse rate is normal or not. The user just needs to attach to the wrist so that the readings are more accurate. There is no need to wait a long time to get readings and ensure long lasting health. 
The Disadvantages of Displaying Health Status Based on the Internet of Things Concept are this tool can not display pulse readings on hand when unable to connect wifi and this causes users not to know the pulse rate. Additionally, the tool is also at high risk for damage if there is a short circuit. This is because when excessive electrical current will occur, short-circuiting can damage the circuit.

\section{Conclusion}

This tool can make it easier for students to manage their health to follow their self-reading. The weakness of this tool is that the tool has less appeal to users to use it. Additionally, this tool needs to be improved with a variety of other functions in order to attract users to use it. Consequently, Displaying Health Status is based on the Internet and still needs to be improved for future.

\section{References}

[1] R. S. Steven, P. Gomes, A. Polotskaia, and M. J. Anna, "The Relationship between Student Health and Academic Performance Implication for School Psychologists," School Psychology International, vol. 32, no. 2, pp. 115-134, 2015.

[2] V. Goel, S. Srivastava, D. Pandit, D. Tripathi, and P. Goel, "Heart Rate Monitoring System Using Finger Tip through IoT," International Research Journal of Engineering and Technology, vol. 5, no. 3, pp. 114-117, 2018.

[3] S. Pasha, "ThingSpeak Based Sensing and Monitoring System for IoT with Matlab Analisys," International Journal of New Technology and Research, vol. 2, no. 6, pp. 19-23, 2016.

[4] M. Tastan, "IoT Based Wearable Smart Health Monitoring System," Celal Bayar University Journal of Science, vol. 14, no. 3, pp. 343-350, 2018.

[5] A. D. Aziz, "Webserver Based Smart Monitoring System Using ESP8266 Node MCU Module," International Journal of Scientific \& Engineering Research, vol. 9, no. 6, pp. 800807, 2018.

[6] Jayalakshmi, and K. Balasubramanian, "Simple Capacitors to Supercapacitors - An Overview," International Journal of Electrochem, vol. 3, pp. 1196-1217, 2008.

[7] S. C. Singh, Basic of Light Emitting Diodes, Characterizations and Applications. India: University of Allahabad, 2014.

[8] A. Malvino and D. Bates, Electronic Principles. New York: McGraw-Hill Education, 2016.

[9] J. Hewes, Building Circuits on Breadboards. United Kingdom: Electronics Club Info, 2013.

[10] U. Gogate, and J. Bakal, "Healthcare Monitoring System Based on Wireless Sensor Network for Cardiac Patients," Biomedical \& Pharmacology Journal, vol. 11, no. 3, pp. 1681-1688, 2018. 